\title{
Mouse Otx2 functions in the formation and patterning of rostral head
}

\author{
Isao Matsuo, ${ }^{1}$ Shigeru Kuratani, ${ }^{1}$ Chiharu Kimura, ${ }^{1,2}$ Naoki Takeda, ${ }^{1}$ and Shinichi Aizawa ${ }^{1,3}$ \\ ${ }^{1}$ Department of Morphogenesis, Institute of Molecular Embryology and Genetics (IMEG), Kumamoto University School \\ of Medicine, Kumamoto 860, Japan; ${ }^{2}$ Department of Molecular and Cell Genetics, School of Life Sciences, Tottori \\ University, Yonago, Tottori 683, Japan
}

The anterior part of the vertebrate head expresses a group of homeo box genes in segmentally restricted patterns during embryogenesis. Among these, Otx2 expression covers the entire fore- and midbrains and takes place earliest. To examine its role in development of the rostral head, a mutation was introduced into this locus. The homozygous mutants did not develop structures anterior to rhombomere 3 , indicating an essential role of $0 t x 2$ in the formation of the rostral head. In contrast, heterozygous mutants displayed craniofacial malformations designated as otocephaly; affected structures appeared to correspond to the most posterior and most anterior domains of Otx expression where Otx 1 is not expressed. The homo- and heterozygous mutant phenotypes suggest Otx2 functions as a gap-like gene in the rostral head where Hox code is not present. The evolutionary significance of Otx 2 mutant phenotypes was discussed for the innovation of the neurocranium and the jaw.

[Key Words: Otx; head development; segmental patterning; homeo box; Otocephaly; cranial neural crest]

Received May 1, 1995; revised version accepted September 7, 1995.

The vertebrate neuraxis can be divided into three regions: the spinal cord, hindbrain, and rostral brain. The hindbrain as well as the somitic mesoderm in the trunk are composed of segmental structures, and recent advances in molecular biology have contributed a great deal to our knowledge of the functions of genes involved in the patterning of this region (McGinnis and Krumlauf 1992). Hox genes stand out among these regulatory genes as the vertebrate relatives of Drosophila homeotic genes HOM-C (Ingham 1988). Evidence that specification of the hindbrain and branchial region is controlled by these Hox genes has been shown in several studies with mutant mice (Kessel and Gruss 1990; Chisaka and Capecchi 1991; Lufkin et al. 1991; Rijli et al. 1993). No Hox code exists at the level of the rostral brain, however; and the existence of a segmental patterning in this region has itself been an intriguing question (Bergquist 1932; Altman and Bayer 1986; Figdor and Stern 1993; Puelles and Rubenstein 1993).

In Drosophila, two genes that contain homeo box domains are expressed in the most anterior part of the head (Finkelstein and Perrimon 1991): empty spiracle (ems) and orthodenticle (otd). The mouse cognates of otd and ems were isolated as Otx1 and Otx2 and Emx1 and Emx2, respectively, and they have nested patterns of expression in the rostral brain of developing mouse embryos (Simeone et al. 1992). The expression domains of these genes are limited both rostrally and caudally, sug-

\footnotetext{
${ }^{3}$ Corresponding author.
}

gesting the presence of a genetic code for the brain regional patterning (Figdor and Stern 1993; Puelles and Rubenstein 1993|. Among Otx and Emx genes, Otx2 expression occurs earliest in the entire epiblast at the prestreak stage (Simeone et al. 1993; Ang et al. 1994). During midstreak stages, the expression domain becomes restricted to the anterior region in all three germ layers, which corresponds to the presumptive rostral head (Simeone et al. 1992; Ang et al. 1994). From these expression patterns, it has been proposed that the Otx2 gene functions to specify territories in the rostral brain of 8-10 days postcoitum $(\mathrm{dpc})$ mouse embryos. To verify this, we generated $O t \times 2$ mutant mice. These mice displayed otocephalic phenotype by haploid insufficiency and loss of rostral head structure by homozygosity, suggesting that the gene does play an essential role in the development of the anterior portion of the head.

\section{Results}

\section{Otocephalic phenotype by heterozygous} Otx2 mutation

Otx2 mutant mice were generated by homologous recombination in TT2 embryonic stem (ES) cells derived from an $\mathrm{F}_{1}$ embryo from C57BL/6 $\times$ CBA mice (Yagi et al. 1993a). The gene was disrupted by inserting the neomycin resistance $\left(n e O^{\mathrm{r}}\right)$ gene into the exon that encodes the homeo box sequence (Fig. 1A), interrupting the sequence between the first and second $\alpha$-helix. The chimeras were obtained normally from two independent mutant ES 
A

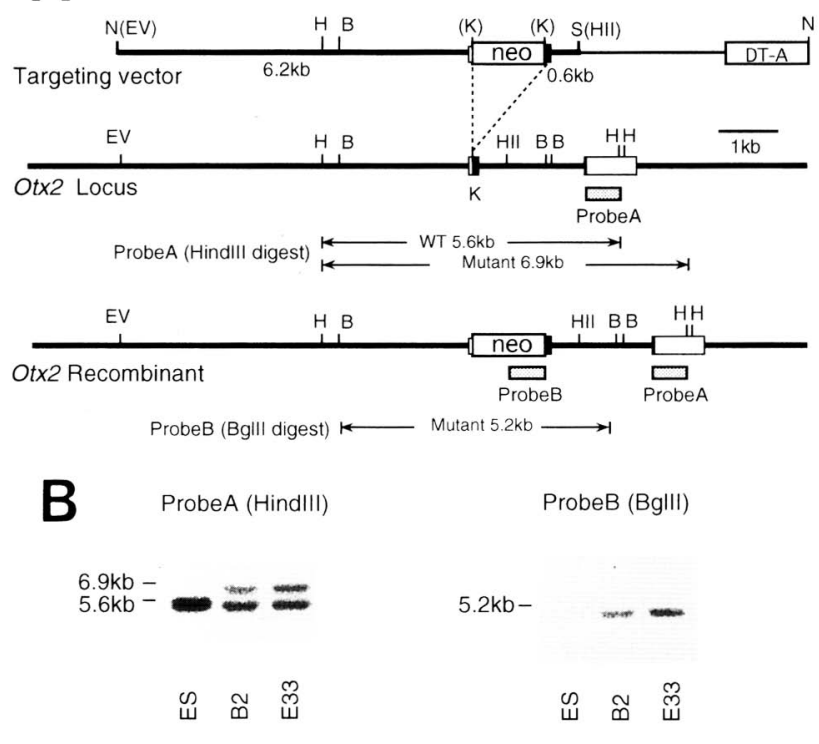

Figure 1. Targeted mutation in the Otx2 locus. $(A)$ Diagrammatic representations of the targeting construct, Otx2 locus, and targeted allele. The neor gene (neo) was inserted into the $K p n I$ site within the homeo box sequence; it was flanked by 6.2 and $0.6-\mathrm{kb}$ homologous sequences at $5^{\prime}$ and $3^{\prime}$ sides (thick lines), respectively. The disruption predicts the expression of an amino-terminal truncated product that contains 61 amino acids of a total 289-amino-acid Otx2 gene product (Simeone et al. 1993). The functional significance of this domain is not yet understood. (DT-A) Diphtheria toxin A fragment gene for negative selection. The thin line indicates the sequences derived from pBluescript (Yagi et al. 1993b). The homeo box-containing exons are shown by boxes; the homeo box itself is in the solid box. The locations of probe A and probe B used for Southern blot analyses are given with the expected sizes of hybridizing fragments below. (B) BgIII; (EV) EcoRV; (HII) HincII; (H) HindIII; (K) KpnI; (N) NotI; (S) Sall. (B) Examples of Southern blot analyses of homologous recombinant (B2 and E33) and wild-type ES cells. (Left) Digested with HindIII and hybridized with probe $\mathrm{A}_{\text {; }}$ (right) digested with $B g I I I$ and probe $B$. The analyses confirmed that there were no random integrations. clones (Yagi et al. 1993a) and mated with C57BL/6 females to generate $F_{1}$ heterozygous mutant mice. Abnormalities were found in these heterozygous mutants: the majority of them died within 1 day after birth with abnormal heads (Fig. 2; Table 1). A few male heterozygous mutant offspring grew to adults normally or with eye malformation, and they were then crossed with C57BL/ 6 females. Most of the $F_{2}$ backcross pups died with malformed heads (mentioned above; Table 1). The occurrence of defects in heterozygous mutants was contradictory to the normal rate of chimera production, as the chimeras were almost exclusively composed of Otx2 heterozygous mutant ES cells even in brain when examined by glucose phosphate isomerase (GPI) analysis (Yagi et al. 1993a; data not shown). The complementation by host embryo-derived cells contributing slightly to the chimeras and/or the effects of the genetic background of the mice could explain this contradiction. The chimeras were then mated with CBA females; most of the $F_{1}$ heterozygous mutant pups from this cross were normal ( $\mathrm{Ta}$ ble 1). Similar results were obtained when heterozygous mutant progeny from C57BL/ 6 females were mated with CBA females (Table 1). In contrast, when $F_{1}$ heterozygous mutants from chimeras and CBA females were mated with C57BL/ 6 females, the majority of pups were abnormal (Table 1). Thus, it appears that the genetic background of CBA mice semidominantly suppressed and that of $\mathrm{C} 57 \mathrm{BL} / 6$ semidominantly induced perinatal death with craniofacial abnormality. Many offspring from CBA females, however, died by the age of 2 months; the cause of death will be determined in future studies. Northern analysis of heterozygotes showed the absence of any truncated products and a decrease of about half in Otx2 expression (data not shown).

In heterozygous mutants from C57BL/ 6 females, external abnormalities were characterized as the loss of the lower jaw and eyes (Fig. 2B-H). Malformations were limited to the cranial region and were never found in the postcranial part of the body. These external phenotypes are reminiscent of otocephalic mutations reported in hu-
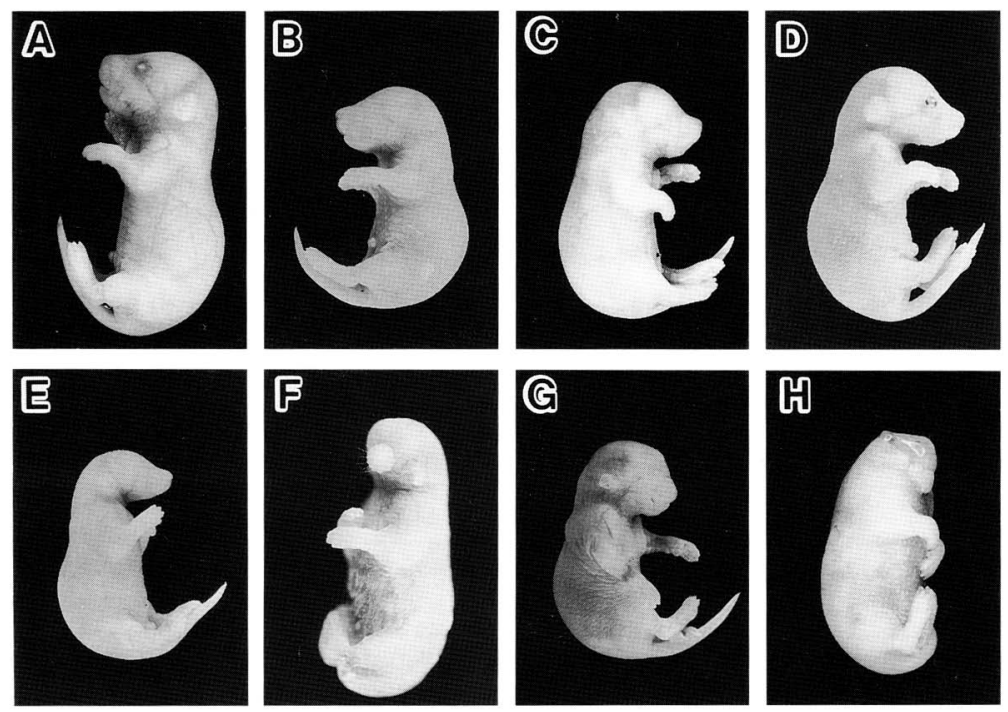

Figure 2. Otocephalic phenotype in Otx2 heterozygous mutants. Lateral views of wild-type $(A)$ and Otx2 $+/-$ mutants $(B-H) . F$ is newborn, and all others are 18.5-dpc embryos. $(B)$ A mutant embryo lacking eyes but with a normal jaw (anophthalmia); $(C)$ an anophthalmic embryo with a small lower jaw (micrognathia); $(D)$ an embryo with a protruding eye and micrognathia; $(E)$ an anophthalmic and agnathic embryo with a narrow head; $(F)$ an ethmocephalic (holoprosencephalic) mouse with a single rod-like nose; $(G)$ an embryo with a short nose; $(H)$ an acephalic embryo with no head. 
Table 1. Effects of genetic background on viability of Otx2 heterozygous mice

\begin{tabular}{|c|c|c|c|c|c|c|c|}
\hline \multirow{2}{*}{\multicolumn{2}{|c|}{ Parental genotype }} & \multirow{3}{*}{$\begin{array}{l}\text { No. of } \\
\text { litters }\end{array}$} & \multirow{3}{*}{$\begin{array}{l}\text { Total no. } \\
\text { pups born } \\
(\%)\end{array}$} & \multicolumn{4}{|c|}{ Offspring genotype $(\%)$} \\
\hline & & & & \multicolumn{2}{|c|}{ alive beyond $24 \mathrm{hr}$} & \multicolumn{2}{|c|}{ died within $24 \mathrm{hr}$} \\
\hline male & female & & & $+1+$ & $+1-$ & $+1+$ & $+1-$ \\
\hline Chimeras & $\mathrm{C} 57 \mathrm{BL} / 6$ & 10 & $63(100)$ & $39(61.9)$ & $6\{9.5\}$ & $1(1.6)$ & $17(27.0)$ \\
\hline $\mathrm{F} 1(\mathrm{~B} 6)^{\mathrm{a}}$ & $\mathrm{C} 57 \mathrm{BL} / 6$ & 21 & $142(100)$ & $77(54.3)$ & $6(4.2\}$ & $4(2.8)$ & 55 (38.7) \\
\hline $\mathrm{BC}(\mathrm{B} 6)^{\mathrm{b}}$ & $\mathrm{C} 57 \mathrm{BL} / 6$ & 4 & $30(100)$ & $19(63.4)$ & $1(3.3)$ & $1(3.3)$ & $9(30.0)$ \\
\hline $\mathrm{BC}(\mathrm{B} 6)^{\mathrm{b}}$ & $\mathrm{CBA}$ & 9 & $57(100)$ & $29(50.9)$ & $27(47.3)$ & $1(1.8)$ & $0\langle 0.0\rangle$ \\
\hline Chimeras & CBA & 10 & $60(100)$ & $37(61.7)$ & $17(28.3)$ & $4\{6.7\}$ & $2\{3.3\}$ \\
\hline $\mathrm{F} 1(\mathrm{CBA})^{\mathrm{a}}$ & $\mathrm{CBA}$ & 7 & $40(100)$ & $23(57.5)$ & $15(37.5)$ & $0(0.0)$ & $2(5.0)$ \\
\hline $\mathrm{F} 1(\mathrm{CBA})^{\mathrm{a}}$ & $\mathrm{C} 57 \mathrm{BL} / 6$ & 7 & $38(100)$ & $17(44.7)$ & $4(10.5)$ & $4(10.5)$ & $13(34.3)$ \\
\hline
\end{tabular}

${ }^{\mathrm{a}} \mathrm{F} 1(\mathrm{~B} 6)$ and $\mathrm{F} 1(\mathrm{CBA})$ : Heterozygous progeny from chimeras mated with $\mathrm{C} 57 \mathrm{BL} / 6$ or CBA females, respectively.

${ }^{b} \mathrm{BC}(\mathrm{B} 6)$ : heterozygous progeny from heterozygous $\mathrm{F}_{1}(\mathrm{~B} 6)$ males backcrossed with $\mathrm{C} 57 \mathrm{BL} / 6$ females.

mans and other animals (Wright and Wagner 1934; Juriloff et al. 1985; Cohen 1989). Otx2 heterozygous mutant phenotypes covered a spectrum, ranging from the lightest case in which the abnormality was not apparent to the most severe case in which most of the head did not develop (Fig. 2H). Most frequent was microphthalmia or anophthalmia plus agnathia $(37.8 \%$; Table 2$)$. Holoprosencephaly (ethmocephaly), short nose, and acephaly were seen in a small fraction of heterozygous mutants (total $7.7 \%$ ) while $16 \%$ appeared to be externally normal (Table 2).

\section{Skeletal anomalies}

The skull showed some anomalies in all of the heterozygous mutants from C57BL/ 6 females, although the degree varied. Abnormality was minimal in heterozygous mutants with no external abnormalities, microphthalmia, or anophthalmia (Fig. 3B,H) and was characterized by the presence of a single or a few foramina in the basisphenoid that might correspond to the posterior end of the trabecular portion in mammals (see Discussion; Kuratani 1989). In some specimens, ectopic ossification centers existed in association with the pterygoid bone (Fig. 3B). There was no obvious anomaly in the mandible (Fig. $3 \mathrm{H}$ ).

In micrognathia, the mandibular bones fused to varying extents (Fig. 3I,J). In some cases, only the anterior tips of the incisors fused while in others the whole mandible involuted into a small single median bone. In agnathia that lacked mandible, Meckel's cartilage and malleus fused in the midline forming a short transverse rod, and incus cartilages were medially shifted. The right and left tympanic bones often fused in the middle (data not shown). In the central stem of micrognathia and agnathia mice, there grew a transverse bar of bone with a cartilaginous nodule beneath the ventral side of the basisphenoid (Fig. 3C). The foramen was anteriorly more expanded (Fig. 3C). Presphenoid, orbitosphenoid, optic foramen, nasal capsule, nasal septum, and ethmoid cartilage were usually deformed and more or less asymmetric (Fig. 3C; data not shown).

The skull defects in holoprosencephaly, short nose, and acephaly were characterized by severe atrophies in the snout. However, no defects were found in the palatine, maxillar, or middle ear components or more posterior structures. In holoprosencephaly, many of the rostral skull bone elements were deformed. Among these, basisphenoid and presphenoid bones were fused together and split into two halves along the midline (Fig. 3D; data not shown). Atrophies were heavier in short nose and acephaly, both of which usually lacked nasal capsule and orbitosphenoid (Fig. 3E,F). In acephaly there were no skull elements anterior to the alisphenoid, including dermal bones in the upper jaw. The cranial base as well as the nasal septum consisted of a pair of rod-like structures that might represent an atavistic configuration of trabecular cartilages (Goodrich 1930; de Beer 1937); the cranial base was split into two halves lateral to an expanded hypophysial foramen (Fig. 3E,F). Consequently, there was no palate of any sort in these skulls. The mandible was absent in holoprosencephaly and acephaly, but the extent of its deformity varied in short nose (Fig. 3K).

\section{Defects in the nervous system}

Abnormalities of the nervous system at early stages were examined by staining with the monoclonal antibody

Table 2. Frequency of external abnormalities of Otx2 heterozygous mice

\begin{tabular}{|c|c|c|c|c|c|c|c|c|}
\hline Total number & NA & Mo & $\mathrm{Mg}$ & Mo Mg & $\mathrm{Mo} / \mathrm{Ao} \mathrm{Ag}$ & $\mathrm{Ec}$ & SN & $\mathrm{NH}$ \\
\hline 156 & 25 & 26 & 10 & 24 & 59 & 4 & 3 & 5 \\
\hline $100 \%$ & $16.0 \%$ & $16.7 \%$ & $6.4 \%$ & $15.4 \%$ & $37.8 \%$ & $2.6 \%$ & $1.9 \%$ & $3.2 \%$ \\
\hline
\end{tabular}

(NA) No apparent abnormalities; (Mo) microphthalmia; (Mg) micrognathia; (Ao) anophthalmia; (Ag) agnathia; (Ec) ethmocephaly (holoprosencephaly); (SN) short nose; (NH) no head (acephaly). 

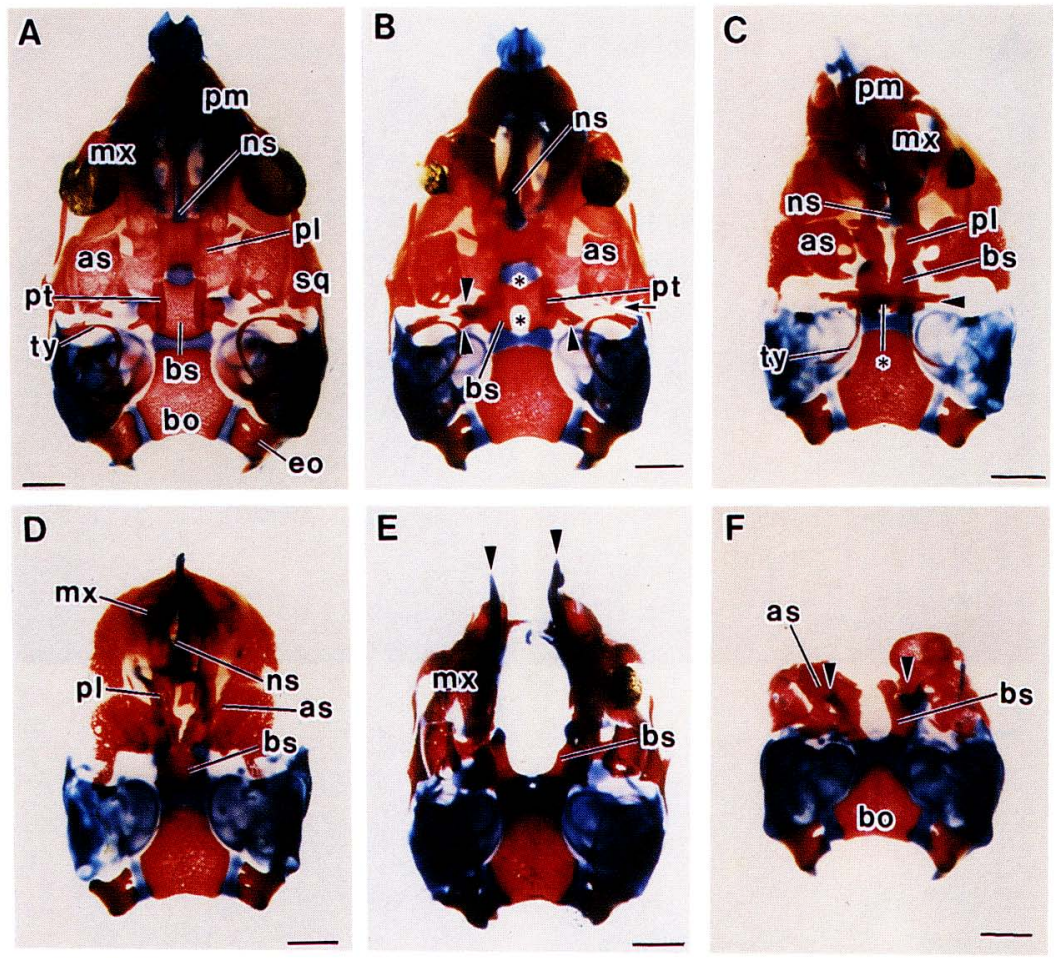

F
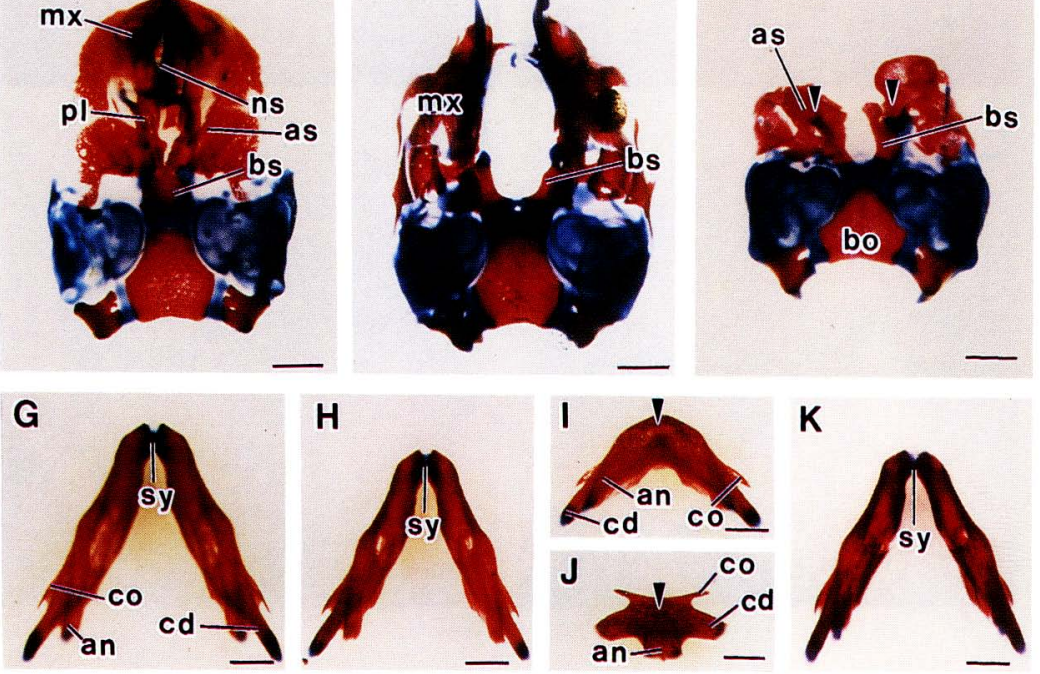

K

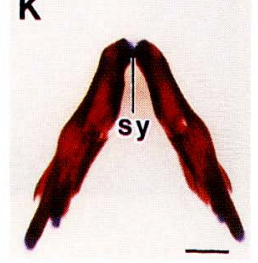

Figure 3. Skull morphologies of Otx2 heterozygotes. Ventral views of the whole-mount skull stained with alcian blue and alizarin red are shown. Mandibles have been separated when they were present $(A-D)$. $(D, F)$ Embryos lacking a mandible. $(A, G)$ Wild-type skulls; $(B-F, H-K)$ heterozygous mutant skulls. $(A)$ The wild-type skull base has a series of medial elements, from caudal to rostral: (bo) Basioccipital; (bs) basisphenoid; presphenoid, and ethmoid bones. Laterally, there are paired bones: (eo) Exoccipital ${ }_{i}$ (as) alisphenoid $_{\text {( }}$ sq) squamosal; (pl) palatine; (mx) maxillar; orbitosphenoid, and premaxillar (pm) bones. $(G)$ The mandible consists of a pair of dermal bones called dentary, each possessing three processes posteriorly, from dorsal to ventral: (co) coronoid, $(\mathrm{cd})$ condyloid, and (an) angular processes. $(B, H) \mathrm{A}$ microphthalmic heterozygous mutant. Note the presence of a single foramen in the basisphenoid (asterisks) and the appearance of ectopic bones associated with the pterygoid (pt; arrowheads). The left incus is fused with alisphenoid (as), reminiscent of their atavistic relationship (arrow). Ventrally, the muzzle appears to develop straight, but the dorsal view shows the asymmetrical configuration of the nasal capsule and septum. (C) A micrognathia, with the nasal capsule bent toward the right side. Beneath the basisphenoid is a transverse bar of ectopic bone fused with pterygoid processes laterally (arrowhead). This bone is associated with the cartilaginous nodule in the center (asterisk). Note an expanded longitudinal slit in the skull base and incomplete development of the optic foramina associated with the atrophic development of the orbitosphenoid. $(I, I)$ Mandibles in micrognathia. They are fused in the middle and lack symphysis (sy); the posterior processes of the mandible are usually present, but in the most severe cases the coronoid process is lost (data not shown). Agnathia is not shown here, as the defects in the cranial base are similar to those of micrognathia $|C|$, and not even a trace of dermal bone was found as a vestige of the mandible. $|D|$ A holoprosencephaly; the mandible is absent. The anterior portion of the skull is atrophic; the whole nasal capsule disappeared into a median rod of cartilage, possibly representing the nasal septum. All of the visceral skeletal elements shift medially, which makes the skull smaller. There is no ectopic transverse bar beneath the basisphenoid, but a small bony nodule is visible. (E,K) A short nose. Note a pair of rod-like structures that might represent an atavistic configuration of the trabecular cartilages (arrowheads). In this specimen, the mandible is apparently normal. $(F)$ An acephaly lacking a mandible. (ns) Nasal; (ty) tympanic. Scale bar, $1 \mathrm{~mm}$.

2H3 (Fig. 4A-D). In the peripheral nervous system (PNS), the wild-type trigeminal nerve develops three major branches by $11.5 \mathrm{dpc}$ : the ophthalmic, maxillary, and mandibular branches. In heterozygous mutants, the ophthalmic branch was specifically affected, ranging in severity from a slight reduction to complete loss of the branch (Fig. 4D; Table 3). In contrast, maxillary and mandibular branches developed normally in all of the heterozygous mutants examined (Fig. 4D; Table 3). The oculomotor and trochlear nerves also frequently displayed anomalies such as poor fasciculation and dorsally directed axonal pathway (Fig. 4B,D; Table 3). No change was observed in the maxilla nerve or more posterior nerves, and defects in the PNS were restricted to the level of the ophthalmic nerve and more anterior nerves (Table 3).
In the central nervous system (CNS), the mesencephalic trigeminal neurons (MT neurons) normally grew axons in the mesencephalic tectum in a ventral direction and then turned caudally to form the mesencephalic trigeminal root (MTR) (Fig. 4A). In heterozygous mutants, the number of MT neurons was often greatly diminished, and their axonal pathway was disturbed (Fig. 4B). Concomitantly, MTR was reduced in thickness and sometimes even lost (Fig. 4B). However, the reticulospinal tract neurons (Windle and Austin 1936) in rhombomere $1|\mathrm{r} 1|$ and $\mathrm{r} 2$ and the initial tracts in the forebrain, such as postoptic commissure and mammillotegmental tract, developed normally in all of the heterozygous mutants examined (Fig. 4B). No abnormalities were found at later stages $(14.5-17.5 \mathrm{dpc})$ in diencephalic axonal tracts such as posterior commissure, hebe- 
Figure 4. Defects in the nervous system of Otx2 heterozygotes. A lateral view is shown of wildtype $(A, C)$ and heterozygous mutant $(B, D) \mathrm{em}$ bryos stained with neuron-specific antibody $2 \mathrm{H} 3$. (A) In a 10.5-dpc wild-type embryo, MT neurons grow axons from the tectum to hindbrain region (arrows). Note the MT tract passing posteriorly through $\mathrm{rl}$ and merging with the trigeminal nerve $\operatorname{root}(\mathrm{V})$ that arises from $\mathrm{r} 2$. The oculomotor nerve (III) extends axons in a ventral direction, and the ophthalmic branch of nerve $\mathrm{V}$ begins to grow axons dorsal to the eye (arrowhead). (B) A $10.5 \mathrm{dpc}$ heterozygous mutant. The number of MT neurons is greatly reduced, and their axonal pathway disturbed (arrows). The ophthalmic branch of the trigeminal nerve has not developed (arrowhead). The oculomotor nerve (III) is poorly fasciculated, and its axons grow more dorsally. The tracts of the forebrain such as the postoptic commissure (po) are present, and the reticulospinal tract grows normally (asterisk). (C) In 11.5-dpc wild-type heterozygotes, the ophthalmic branch $\left(V_{1}\right)$ of nerve $V$ reaches the nasal region (arrowhead). (D) A 11.5$\mathrm{dpc}$ heterozygous mutant, the ophthalmic branch frequently is lost completely (arrowhead) while the maxillomandibular portion $\left(V_{2}, V_{3}\right)$ develops normally. The trochlear nerve (IV) shows poor fasciculation. (VII) Facial nerve; (IX) glossopharyngeal nerve. Scale bar, $250 \mu \mathrm{m}$.
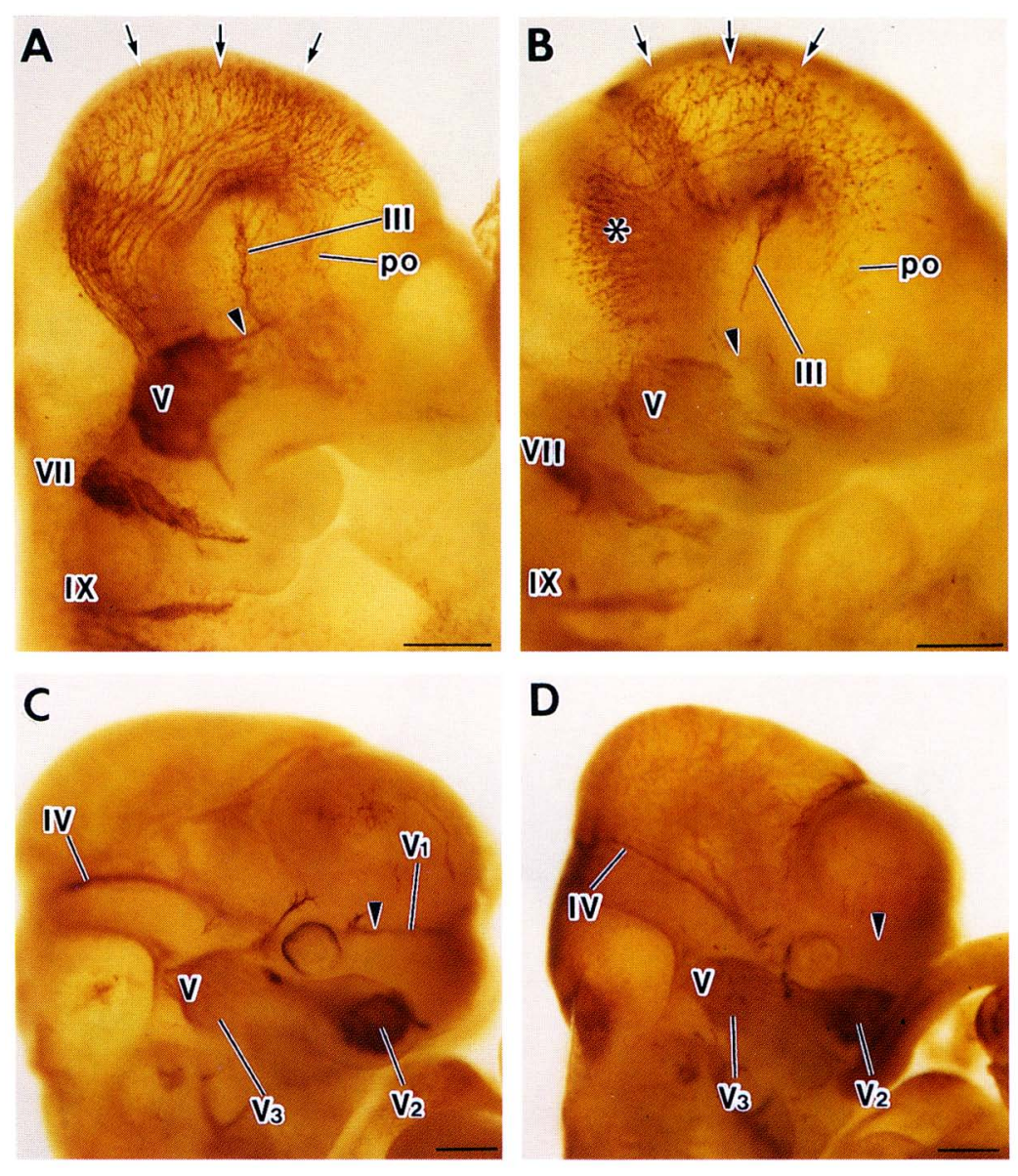

nulopeduncular tract, stria medullaris, or mammilothalamic tract (Fig. 5E; data not shown).

The anatomy of the forebrain and midbrain was analyzed histologically. In acephaly, the entire fore- and midbrains were lost, but most of the hindbrain and spi-

Table 3. Frequency of defects in the nervous system at 10.5 and $11.5 \mathrm{dpc}$

\begin{tabular}{lc}
\hline Type of nerve & Number defected/examined \\
\hline TPOC & $0 / 14$ \\
MTT & $0 / 14$ \\
Nerve III & $4 / 10$ \\
Nerve IV & $13 / 22$ \\
MT neurons & $16 / 19$ \\
Nerve $V_{1}$ & $24 / 30\left(9^{\mathrm{a}} / 22\right)$ \\
Nerve $\mathrm{V}_{2+3}$ & $0 / 30$ \\
Reticulospinal neurons & $0 / 8$ \\
Nerve VII & $0 / 30$ \\
Nerve IX & $0 / 30$ \\
Nerve X & $0 / 30$ \\
\hline
\end{tabular}

(TPOC) Tract of the postoptic commissure; (MTT) mammillotegmental tract; (MT neurons) mesesncephalic trigeminal neurons.

${ }^{a}$ Complete loss of the ophthalmic branch of the trigeminal nerve (nerve $\mathrm{V}_{1}$ ) at $11.5 \mathrm{dpc}$. nal cord were present and normal (Fig. 5A). In holoprosencephaly, the choroid plexus was absent at the telencephalon level, and the third ventricle did not grow a pair of lateral ventricles but remained as an enlarged median vesicle (Fig. 5B,C). In the remaining heterozygous mutants, development of the inferior colliculus was frequently arrested (Fig. 5D,E). Other mesencephalic structures such as the red nucleus and substantia nigra developed normally, and no anomalies were apparent in the telencephalon or diencephalon. Of note, however, is the deformity of the posterior lobe of the hypophysis (adenohypophysis/ in most of the heterozygous mutants, and some of them lacked both anterior and posterior lobes (Fig. 5G,H).

\section{Defects in sensory organs}

Sensory organs also showed anomalies in Otx2 heterozygous mutants. In anophthalmia, only a trace of pigmented cells was present with remnants of extrinsic eye muscles (Fig. 6F), but vestigial optic chiasms were normally present. In microphthalmia, the eyes were often dislocated, either protruding prominently over the surface of the face or deeply buried in the orbit (Fig. 6D-F). Retina and pigment epithelial layers were hyperplastic and sometimes folded several times within a single eye- 

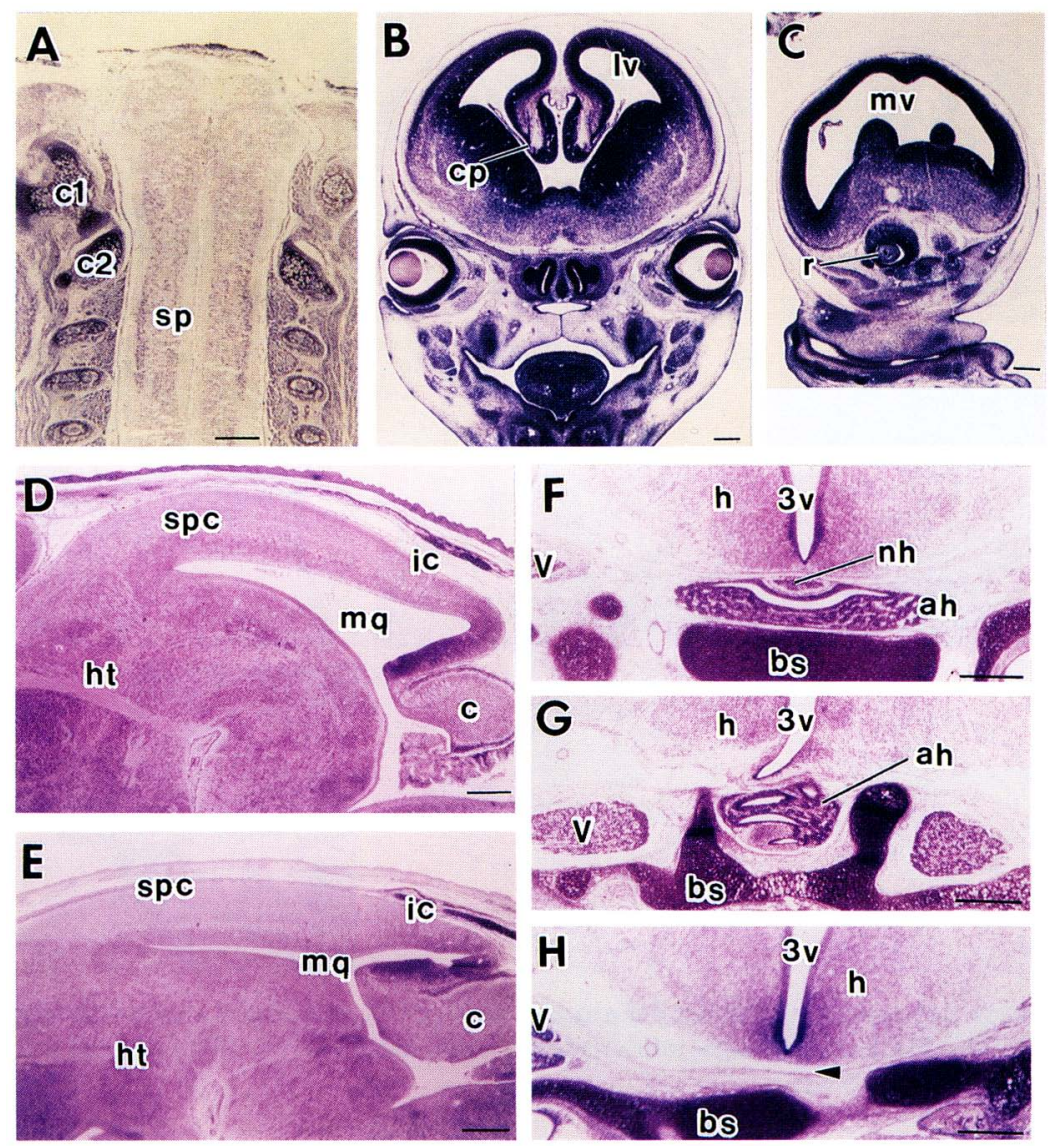

Figure 5. Brain architecture in Otx2 heterozygous mutants. $|A|$ The horizontal section of an acephalic brain at $17.5 \mathrm{dpc}$. Structures corresponding to mid-, fore- and rostral hindbrain are lacking. $(B, C)$ Frontal sections of 14.5-dpc wild-type and ethmocephaly (holoprosencephaly) embryos at the telencephalon level, respectively. The wild-type embryo has two lateral ventricles (lv) and a choroid plexus (cp) while the ethmocephalic embryo has an enlarged single median ventricle $(\mathrm{mv})$ and no choroid plexus. $(D, E)$ Frontal sections of 17.5dpc tectum; wild-type normal and heterozygous arrested inferior colliculus (ic), respectively. $(F)$ Wild-type hypophysis with neurohypophysis [(nh) anterior lobe] and adenohypophysis [(ah) posterior lobe]. (G) Hypophysis in an agnathia heterozygote. The anterior lobe is deformed, and no posterior lobe is recognizable. $(H)$ A short nose heterozygous mutant. Note the absence of the hypophysis (arrowhead). (bs) Basisphenoid; (c) cerebellum; (cl) first cervical vertebra (atlas); (c2) second cervical vertebra (axis); (h) hypothalamus; (ht) habenulopeduncular tract; $(\mathrm{mq})$ mesencephalic aqueduct; $(\mathrm{r})$ retinal layer; (sp) spinal cord; (spc) superior colliculus; (3v) third ventricle. Scale bar, $250 \mu \mathrm{m}$. ball. Such abnormal eyes usually lacked lens, cornea, and iris but possessed eyelids, sclera, optic nerve, and extrinsic eye muscles (Fig. 6F,I). The ciliary ganglion that originates in the mesencephalic neural crest (Le Douarin 1982) was also frequently affected and absent when eyes were heavily deformed (data not shown).

The olfactory epithelium, nasal cavity, vomeronasal organ (Jacobson's organ), and nasal septum were present in the wild-type nasal capsule by $17.5 \mathrm{dpc}$ (Fig. 6A). In most of the heterozygous mutant embryos, nasal cavities were more or less deformed and had asymmetrical configuration. In severe cases, the nasal septum, Jacobson's organ, and olfactory epithelium were greatly involuted or lacking entirely (Fig. 6D,G). The olfactory bulb was absent when the forebrain was heavily deformed. In contrast, no anomalies were apparent in the inner ear.

\section{Abnormalities in the cranial neuroepithelium of Otx2 heterozygous embryos}

Most of the cranial defects in Otx2 heterozygous mutants are restricted to Otx2 expression in the cranial neuroepithelium at $\sim 9.5-10.5 \mathrm{dpc}$ (see Discussion). The histological abnormality commonly observed at this stage in heterozygous mutants was retardation in rostral brain development-the neuroectoderm was thinner (Fig. 7B arrows), and the number of mitotic cells was smaller in the mesencephalon. However, no pyknotic cells were apparent. In the wild-type embryo, the constriction between mid- and hindbrains is distinct, where Otx2 expression is posteriorly demarcated (Fig. 7A,C). In the heterozygous mutants, the constriction is obscured. Concomitantly, Otx2 expression does not have a sharp boundary and is expressed more posteriorly in the hindbrain beyond the isthmus (Fig. 7B,D). However, no change was obvious in the En2 expression pattern that is broadly expressed around this junction at $10.5 \mathrm{dpc}$ (Fig. $7 \mathrm{E}, \mathrm{F} \mid$. Abnormalities were not apparent in the neuroectoderm of the postcranial region.

\section{Lack of rostral head in Otx2 homozygous mice}

Analyses of the homozygous mutant phenotype were hindered, as the number of fertile heterozygous mutant females surviving beyond 2 months of age was limited. The frequency analysis of homozygous mutants was not thorough enough at stages earlier than $7.5 \mathrm{dpc}$, and earlier defects that might occur in these mutants will be studied in the future. Homozygous mutant embryos, however, were able to develop beyond $8.5 \mathrm{dpc}$, although growth was markedly retarded and the embryos had not started turning. Homozygous mutants were never found beyond $10 \mathrm{dpc}$. Remarkably, in these homozygous mutant embryos, structures corresponding to the rostral 
Figure 6. Defects in the sensory organs of Otx2 heterozygous mutants. Frontal sections through the heads of wild-type $(A-C)$ and Otx2 heterozygous mutant $(D-I)$ embryos at $17.5 \mathrm{dpc}$. $A, D$, and $G$ are at the level of the nasal septum; others are at eye level. Milder $(D-F)$ and heavier $(G-I)$ micropthalmia/anophthalmia and agnathia heterozygous mutants are shown. $(D)$ The eye primordia (ep) protrude over the facial surface. Nasal cavities and nasal capsule are deformed, and the nasal septum (n), Jacobson's organ, the olfactory epithelium, and the tongue are absent. The nasopharynx and palatal shelf are not formed. $(E)$ An eye primordium is deeply buried in the orbit, with a thick retinal layer $\{r \mid$ and pigment epithelium $(\mathrm{p})$. The lens, cornea, iris, and retinal layer are absent. $(F)$ The pigment epithelium (p), eyelids (el), and extrinsic ocular muscles (em) are deformed. $(G)$ No nasal structures such as nasal septum, Jacobson's organ, or nasal epithelium are present. $(H)$ The right eye is completely absent, together with the optic nerve and extrinsic eye muscles. The left eye protrudes over the surface. No tongue or palatal shelf was seen. Note the presence of the olfactory bulb (ob). (I) The protruding eye has thickened and folded ret-
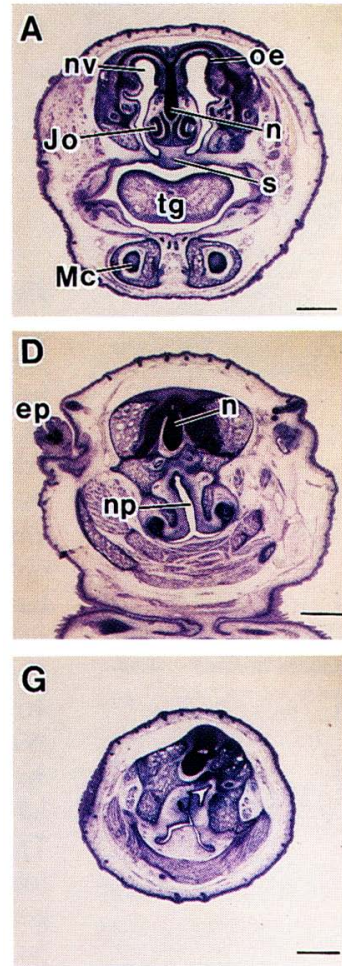
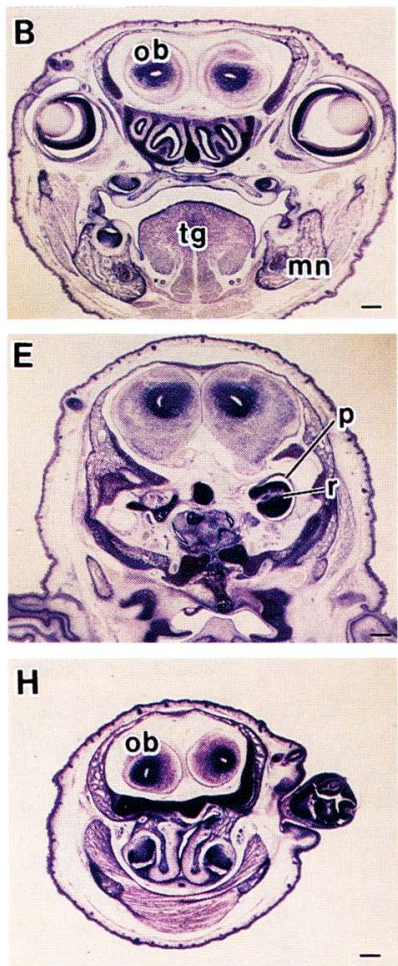
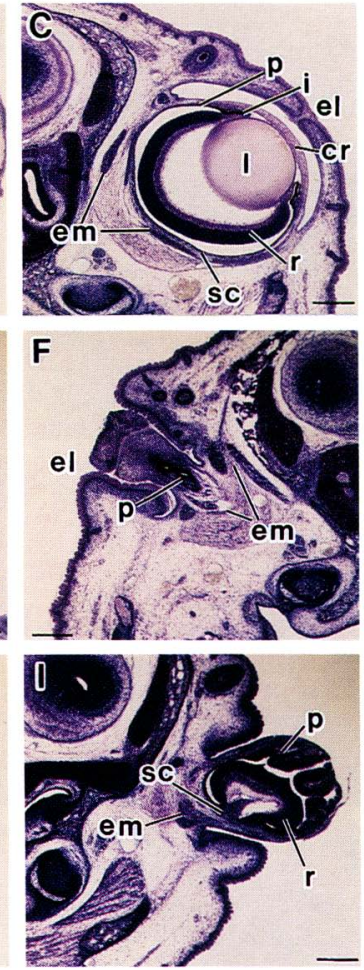
inal and pigment layers. Extrinsic ocular muscles, the sclera (sc), and the eyelids are deformed. The lens, iris, and cornea are completely absent. (cr) Cornea; (i) iris; (Jo) Jacobson's organ; (l) lens; (Mc) Meckel's cartilage; (mn) mandible; (np), nasopharynx; (nv) nasal cavity; (oe) olfactory epithelium; (s) palatal shelf; $(\mathrm{tg})$ tongue. Scale bar, $250 \mu \mathrm{m}$.

head were absent (Fig. 8A-C). Histologically, trunk structures such as neural plate and somites were normally present, but anterior structures such as heart and foregut were absent (Figure $8 \mathrm{D}, \mathrm{E}$ ).

To determine the axial level lost in homozygous mutants, expression of three molecular markers, Brachyury, Krox-20, and En2 was examined. Brachyury, a marker of notochord (Herrmann 1991), was normally expressed, but it extended to the anterior end in the homozygous mutant embryos (Fig. 9 A,B). Krox-20, a marker for $r 3$ (Wilkinson et al. 1989), was expressed at the most anterior end of the homozygous mutants; presumably the end corresponds to the $\mathbf{r} 3$ region, although it is slightly reduced in size (Fig. 9D arrowhead). En2, a marker for the presumptive boundary between mesencephalon and metencephalon (Davis et al. 1988), was not expressed in the mutant embryos (Fig 9F). This indicates that the neuraxis of the Otx2 homozygous embryos was rostrally truncated at the level rostral to 3 , lacking all of the anterior structures including fore- and midbrains.

\section{Discussion}

The Otx2 mutant presents several intriguing insights into the formation and patterning of the vertebrate head. Homozygous mutants have revealed the role of Otx2 in genesis of the neuraxis. Heterozygous mutants have suggested its role at subsequent stages that could not be shown in homozygous mutants because of developmental arrest at earlier stages. Defects in Otx2 homo- and heterozygous mutants were restricted to the anterior portion of the head, and no structural anomalies were found in more caudal regions of the body where Hox code is present. The heterozygous mutant phenotype is especially interesting beyond the problem of the phenotypic diversity inherent in haploid insufficiency. The affected regions coincided with the most caudal and most rostral regions of the Otx2 expression in the rostral brain, where neither $O t x 1, E m x 1$, nor $E m x 2$ genes is expressed. The phenotype suggests that the gene participates in patterning of the rostral head, as expected from its expression pattern (Simeone et al. 1992).

\section{Otocephaly (agnathia-holoprosencephaly)}

In humans, many agnathia-holoprosencephaly syndromes exist, including the autosomal dominant form with incomplete penetrance and remarkable variability in phenotype (Cantu 1978; Cohen 1989). The chromosome location of the human OTX2 maps to $14 \mathrm{q} 21-22$ (Kastury et al. 1994), and the proximal 14 trisomy has been shown to cause holoprosencephaly with craniofacial abnormalities (Cottrall et al. 1981). Several otocephalic mutations have been reported in mammals: a dominant one in guinea pig (Wright and Wagner 1934) and two recessive ones in mice designated as $j a w(j)$ and oto- 

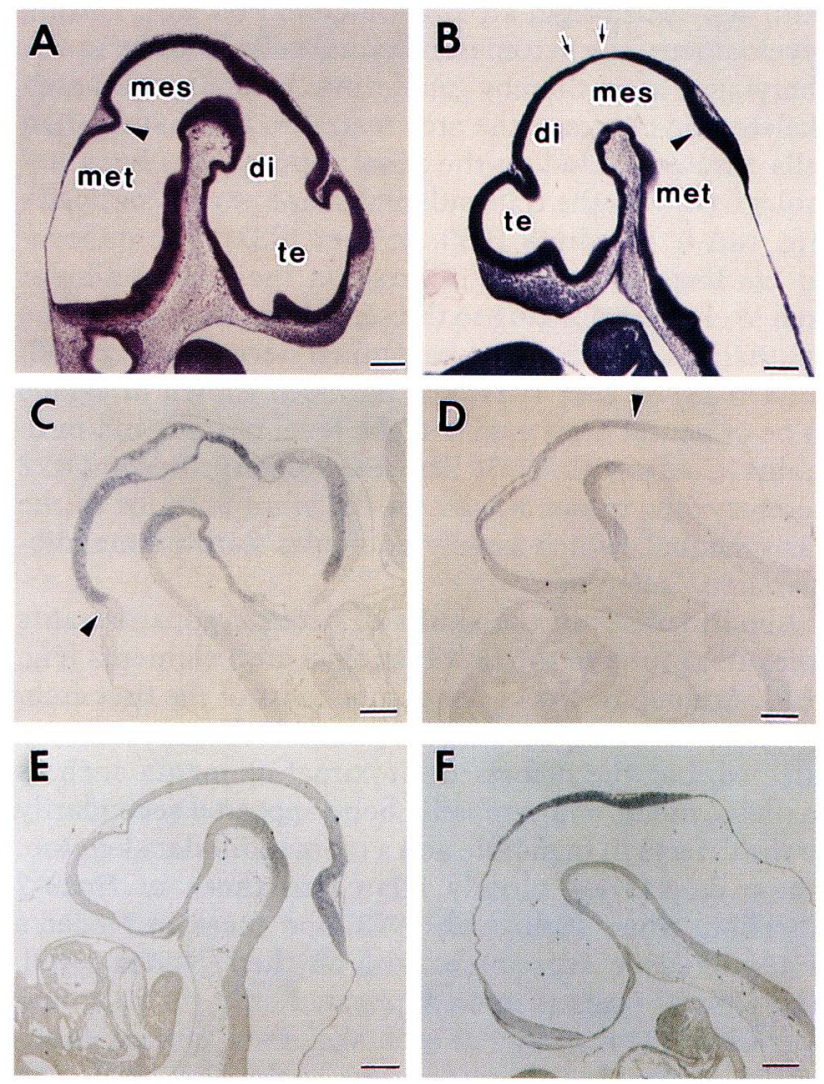

Figure 7. Cranial neuroepithelium in 10.5-dpc heterozygous mutant embryos. Sagittal histological views $(A, B)$, and Otx2 $(C, D)$ and $E n 2(E, F)$ expression are shown by in situ hybridization in wild-type $(A, C, E)$ and heterozygous mutant $(B, D, F)$ embryos, respectively. Arrowheads indicate the constriction between mid- and hindbrains. Note that the constriction is obscured in heterozygous mutants. Also note that the mutant neuroectoderm is thinner in the mesencephalon (arrows). Scale bar, $200 \mu \mathrm{m}$.

cephaly (oto) (Little and Bagg 1924; Juriloff et al. 1985). The oto locus appeared to be linked closely to chromosome 1 , and its penetrance was dependent on the genetic background of mice, being nearly complete in C57BL/ 6 strain background (Juriloff et al. 1985). In mice, Otx2 maps to chromosome 15 (M. Oyanagi, M. Ohashi, I. Matsuo, S. Aizawa, and R. Kominami, in prep.). In humans, agnathia-holoprosencephaly has been observed in the fetal alcohol syndrome, and it has been demonstrated in mice that brief exposure to ethanol on gestational day 7 or 8 is sufficient to produce the otocephalic phenotype in C57BL/ 6 background (Sulik et al. 1981). Several genes appear to be involved in otocephaly, and C57BL/ 6 mice might have mutations in one or more of these genes.

Of note is the variability of phenotypes in all of the otocephalic mutants reported. The variable phenotype in Otx2 heterozygous mutants raised the question about the nature of the mutation we created. Absence of body structures in homozygous mutants that express Otx2 made it impossible to analyze the possible production of truncates that can function dominantly. This could not be examined by RT-PCR (reverse transcription-polymerase chain reaction) assay on heterozygous mutants because of the presence of the normal allele. Limited amount of mRNA in this stage of embryos did not allow Northern blot analysis on each heterozygous mutant. Under this restriction, the conclusion has to be tentative, but the Northern analysis of heterozygous mutants favors the null nature of gene disruption, and the phenotypes may be attributable to haploid insufficiency.

\section{Mesencephalic origin of neural crest in affected structures}

Defects in Otx2 heterozygous mutants were restricted to the anterior portion of the head, and no anomalies were found in more caudal regions of the body, including the hindbrain level where the Hox code is present. Among the abnormalities observed, many were apparently attributable to defects of the neural crest and its closely related derivatives in the mesencephalon. For example, in amphibians, the MT neurons have been shown to develop from the mesencephalic neural crest (Piatt 1945). The trigeminal ganglion is of both neural crest and epibranchial placode origin (Hamburger 1961), and the neural crest component of the ophthalmic lobe has been mapped at the midbrain level in mammals /Tan and
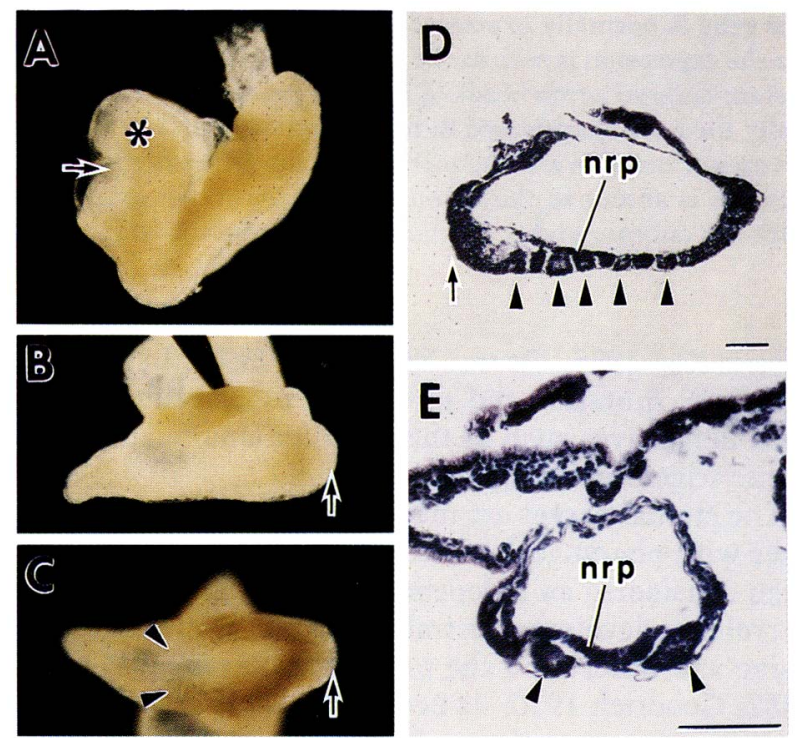

Figure 8. Loss of rostral head structures in Otx2 homozygous mutant embryos. A lateral view of wild-type $(A)$ and lateral $(B)$ and ventral $(C)$ views of homozygous mutant $8.5 \mathrm{dpc}$ embryos is shown. Sagittal $(D)$ and frontal $(E)$ sections of homozygous mutant $8.5 \mathrm{dpc}$ embryos are also shown. An asterisk indicates the rostral head in $A$, and arrows indicate the anterior end of the homozygous mutant embryos $(B, C, D)$ and the corresponding region in a wild-type embryo $(A)$. Development of somites is indicated by arrowheads in $C-E$. (nrp) neural plate. No heart or foregut has been found in homozygous mutants. Scale bar, 100 $\mu \mathrm{m}$. 

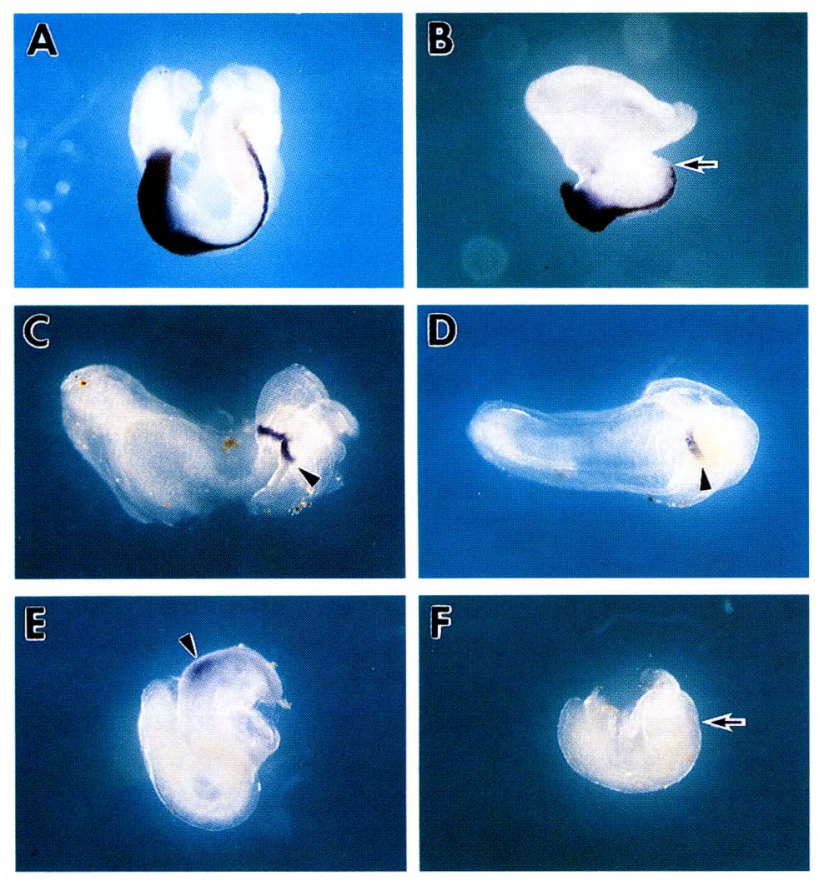

Figure 9. Neuraxis formation in homozygous mutant embryos. Whole mount in situ analysis in wild-type $(A, C, E)$ and homozygous mutant $(B, D, E)$ 8.5-dpc embryos is shown. $(A, B)$ Brachyury expression patterns. Normally, expression is restricted to the notochord and is not in the prechordal mesoderm. In the homozygous mutant embryo, the gene is expressed in the anterior end (arrow). $(C, D)$ Krox-20 expression patterns. The gene is normally expressed in $\mathrm{r} 3$ (arrowhead) at this stage, but the expression is seen at the anterior end in the homozygous mutant embryo (arrowhead). (E,F) En2 expression patterns. Normally the gene is expressed in the presumed boundary between the mesencephalon and the metencephalon (arrowhead), but expression is absent in the homozygous mutant. An arrow indicates the anterior end of the homozygous mutant embryos.

Morris-Kay 1985; Osumi-Yamashita 1994). In contrast, the Otx2 mutation did not affect more caudal neural crest derivatives such as the maxillomandibular portion of the trigeminal ganglion.

The cranial nerves are metamerically organized in register with pharyngeal arches. The ophthalmic nerve has been considered an independent nerve /called profundus nerve) that developed rostral to the rest of the trigeminal nerve and innervated the premandibular area (Marshall 1882; Goodrich 1930; de Beer 1931). This branch has its own nerve root in lower animals (Fig. 10B; Goodrich 1930) and develops as an independent ganglionic primordium even in amniotes (Hamburger 1961). Although it is not clear whether the crest destined for the ophthalmic ganglion is distinguishable from that giving rise to the maxillo-mandibular ganglion, it is probable that the rhombencephalic crest cells populate the latter (Lumsden et al. 1991).

The vertebrate skull is originated from a large amount of neural crest-derived ectomesenchyme (Noden 1984). Deformed elements in the Otx2 heterozygous mutant skull and their origin are illustrated in Fig. 10A. During development, the ectomesenchymal cells localize in the pharyngeal arch, thereby generating the pharyngeal arch skeleton. In contrast, the area rostral to the mammalian sella turcica, including the nasal septum, has been homologized with the trabecular cartilage phylogenetically (Fig. 10A,B; Goodrich 1930; de Beer 1937). The trabecular cartilage most likely represents the premandibular arch skeleton belonging to the same head segment as the ophthalmic branch of the trigeminal nerve (see Fig. 10B; Allis 1923; de Beer 1931) and has been shown in avians to be of neural crest origin at the level of fore- and midbrains (Couly et al. 1993). The major deformities in Otx2 heterozygous mutants were in the skull anterior to the basisphenoid, which largely coincides with premandibular arch skeletons.

Abnormalities in the skulls of heterozygous mutants were also found in the first branchial arch elements (Fig. 10A). Among the lower jaw components of the first arch, the distal element, the dentary (mandible), was primarily affected, but the defects in proximal elements such as malleus, incus, and tympanic bone appeared secondarily to the defects in mandible and a premandibular skeleton. These defects are closely related to those in Hoxa-2 knockout mice (Rijli et al. 1993) and those in Noden's transplantation experiment with chicken (Noden 1983). The Hoxa-2 mutant mice duplicated only the proximal portion of the mandibular arch skeletons, and no duplication occurred in the distal part of the first arch-the mandible (Rijli et al. 1993). When the neural crest at boundaries between mesencephalon and rhombomere was transplanted into the second arch level, the proximal portion of the mandibular arch skeletons was duplicated completely and the distal portion only partially (Noden 1983). The Otx2 gene is expressed in the ectomesenchyme of the first arch (Ang et al. 1994, I. Matsuo, and S. Aizawa, unpubl.), which was recently found to originate partly from the mesencephalon and partly from the hindbrain (Osumi-Yamashita et al. 1994). Thus, it is possible that the mandibular arch ectomesenchyme is composed of heterogeneous cell populations with different genetic codes for neuraxial origins. The distal part of this arch might be under the Otx2 gene and thus destined to develop mandible and the proximal part under the default state of Hox or Otx being destined to develop middle ear structures.

\section{Implication for the Otx 2 function in head morphogenesis}

Around $7.5 \mathrm{dpc}$ the Otx2 gene is normally expressed in the anterior region that corresponds to the presumptive rostral head when Otx1, Emx1, and Emx2 are not expressed. Responsibility for the absence of rostral head structures in homozygous mutants may reside in this Otx2 expression, indicating its essential role in the formation of the rostral head. Lim1 knockout embryos also failed to form anterior head structures (Shawlot and Behringer 1995). Lim1 expression occurs in anterior mesoderm, and Otx2 expression in the anterior neuro- 


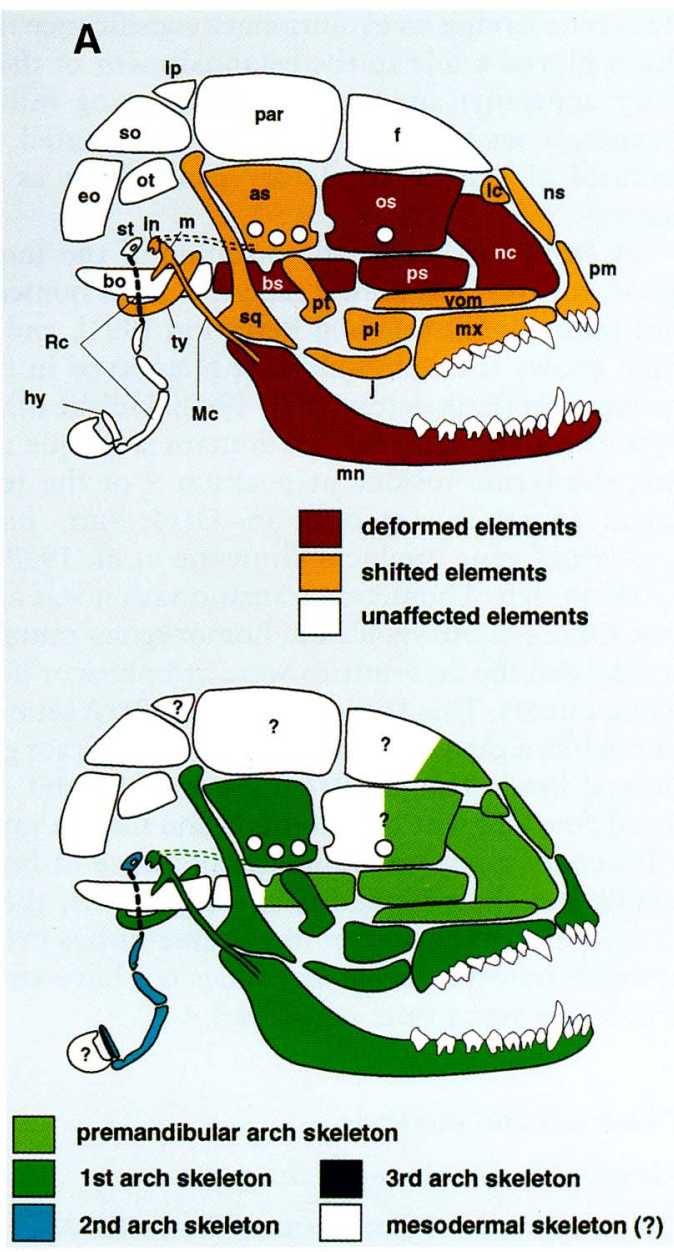

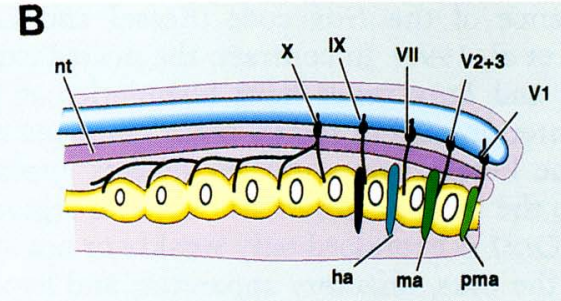

Hypothetical ancestor

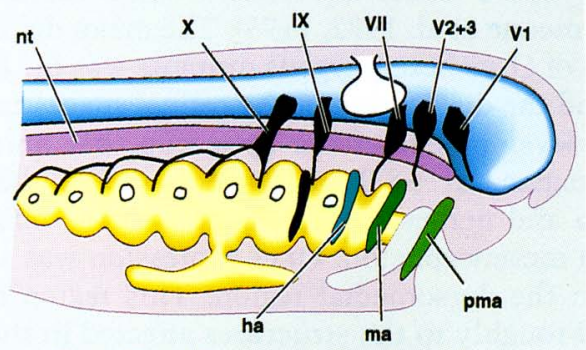

Agnatha (Ammocoetes larva)

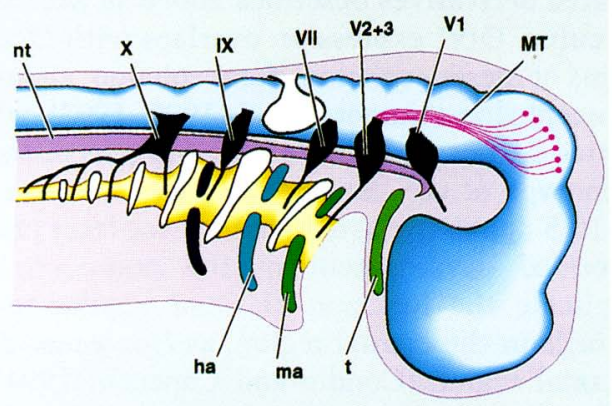

Gnathostomata (Shark embryo)

Figure 10. Evolutionary implications of skull defects in Otx2 heterozygous mutants. $|A|$ Affected elements in the heterozygous mutants almost colocalize with those derived from premandibular and mandibular arch ectomesenchyme. (Top) Skeletal elements affected in Otx2 heterozygous mutants are superimposed onto the scheme of a generalized mammalian skull (Evans 1979). Broken lines connecting the incus and the alisphenoid represent the primitive state of the palatoquadrate cartilage. This connection appeared in the heterozygous mutant skull (see Fig. 3B, arrow). (Bottom) Origins of mammalian skeletal elements are extrapolated from data obtained in experiments with avian embryos (Le Douarin 1982; Noden 1984; Couly et al. 1993). There are different opinions as to the origin of the dermal skull roof (Noden 1984; Couly et al. 1993), and the origin of the mammalian orbitosphenoid is also enigmatic, which are labeled with a question mark (?). Note that no hyoid arch-derived elements are deformed. (f) Frontal; (hy) hyoid; (in) incus; (ip) interparietal; (i) jugal; (lc) lachrymal; (m) malleus; (nc) nasal capsule; (os) orbitosphenoid; (ot) otic capsule; (par) parietal; (ps) presphenoid; (Rc) Reihert's cartilage; (so) supraoccipital; (st) stapes; (vom) vomer. For other abbreviationss, see the legend to Fig. 3. $(B)$ Evolution of the vertebrate head based on the diagram by de Beer (1931), with slight modifications. (Top) Hypothetical vertebrate ancestor with simple metamerism. Each pharyngeal arch is associated with a single skeletal bar and a cranial nerve. (Middle) Agnathan state (larval form of an extant cyclostome, lamprey). The anterior end of the neural tube begins to expand, but the jaw is not yet formed. Note the presence of the anterior-most (premandibular) pharyngeal arch skeleton (pma) in front of the future mouth. (Bottom) Gnathostome state. Anterior pharyngeal arch skeletons were utilized to create masticatory apparatus and a new neurocranium. The Otx2 gene is expressed throughout the entire region involved in these events. (ha) Hyoid arch skeleton; (ma) mandibular arch skeleton; (MT) mesencephalic trigeminal tract; (nt) notochord; $(\mathrm{t})$ trabecular cartilage; (V1) profundus or ophthalmic branch of the trigeminal nerve; $(\mathrm{V} 2+3)$ maxillomandibular portion of the trigeminal nerve; (VII) facial nerve; (IX) glossopharyngeal nerve; (X) vagus nerve.

ectoderm is supported by anterior mesoderm (Ang et al. 1994). How Otx2 and Lim1 interact in the development of the rostral head is an important issue for future studies.

At the subsequent pharyngula stage, $\sim 8.5-10.5 \mathrm{dpc}$, nested expressions are established among Otx2, Otx1, $E m \times 2$, and $E m x 1$ genes in the cranial region. Like Hox genes, the $O t x 2$ gene is not only expressed in the central nervous system (CNS) but also in multiple cell lineages and has been assumed to function in the local morphogenesis of the head segments. The Otx2 heterozygous mutant phenotypes are consistent with this assumption. The expression of Hox genes has different boundaries at the rostral end, and loss-of-function mutations of these genes result in the abnormal development of structures derived from the most rostral region, demonstrating pos- 
terior prevalence of the Hox code (Kessel and Gruss 1990; Lufkin et al. 1991). In contrast, the nested expressions of Otx and Emx genes have boundaries at both caudal and anterior ends in rostral brain (Simeone et al. 1992), and the heterozygous mutant defects appear to correspond to the most posterior and anterior regions of Otx2, where Otx1 is expressed only weakly or not at all.

Defects in the eyes, olfactory apparatus, and hypophysis may correspond to Otx2 expression at the most anterior part where Otx1, Emx1, and $E m \times 2$ are not expressed (Simeone et al. 1992, 1993). The major deformity in the eyes of Otx2 heterozygous mutants was the loss of the lens and the dislocation of the retina, suggesting the disturbed development of the optic cup that normally begins to expand at $\sim 8.0 \mathrm{dpc}$. Defects in the olfactory epithelium and nerves suggest defects in the olfactory placode. In mesencephalon, Otx1 expression was absent or weak in the dorsomedial region. This region might correspond roughly to the structures affected in the majority of Otx2 heterozygous mutants: neural crest and its closely related derivatives described above as well as inferior colliculus. Otx1 expression overlaps with Otx2 in other regions of mesencephalon, diencephalon, and most of the telencephalon (Simeone et al. 1992, 1993), where abnormalities are not apparent in heterozygous mutants.

The phenotype of the heterozygous mutant neuroectoderm at $10.5 \mathrm{dpc}$ is consistent with these later phenotypes. Retarded development of the neuroectoderm might implicate the function of Otx2 regulating the growth of cells in the cranial region, as Hox genes do in the postcranial region (Condie and Capecchi 1994). In addition, loss of a clear boundary between mid- and hindbrains in Otx2 expression in heterozygous mutants (Fig. 7D) might implicate the autoregulatory circuits in the expression of this gene. The details of processes leading to the later defects, however, are yet to be determined.

\section{Otx2 and vertebrate head evolution}

The invention of the masticating jaw is one of the most important innovations in the entire history of vertebrates (Fig. 10B). In the transition from agnathan to gnathostome states, the pharyngeal arch skeletons play a leading role. The mandibular arch skeleton forms the masticating jaw. Sensory elements derived from the mesencephalic neuroepithelium have been incorporated into this masticatory system as MT neurons to control the force of the bite. Simultaneously, the anterior region of the neural tube expands beyond the anterior tip of the notochord to form the rostral brain. The mesoderm is not available to form the neurocranium in this region; instead, the premandibular arch skeleton, the trabecular cartilage, may have formed a new neurocranium to support the expanding brain (see Fig. 10B; Romer and Parsons 1949). This secondary neurocranium corresponds to the "new head" (Gans and Northcutt 1983). Cyclostomata, which has no mandible, does not possess MT neurons either (Weinberg 1928). Defects of the mandible, MT neurons, and anterior neurocranium as well as ophthalmic nerve in Otx2 heterozygotes might implicate this gene having an evolutionary significance that would have played a role in the establishment of the masticatory apparatus and neurocranium using different segments; a set of genes might be coordinated under the control of several regulatory genes such as the Otx2 gene.

In Drosophila, otd, the ortholog of the mouse Otx2 gene, functions as both a gap gene and a homeotic selector gene (Finkelstein and Perrimon 1991), and its mutation shows the semidominant phenotype in ocellar development (Finkelstein et al. 1990). Unlike other homeo box genes, the Otx2 homeo domain is unique in possessing the lysine residue at position 9 of the recognition helix found so far only in Otx1, otd, bicoid, and goosecoid gene products (Simeone et al. 1993). In addition, no sign of homeotic transformation was apparent in the Otx2 heterozygous and homozygous mutant phenotypes, and the deformities were atrophies or deletions of components. This suggests that the Otx2 gene would act more like a gap gene than a homeotic selector gene in the rostral head. The similar roles of Otx2 and otd in the head development of mammals and insects raises an evolutionary question about the presence of homologous genes and their functions in Amphioxus, the relatives from which the ancestor of vertebrates has evolved. The animal, however, apparently does not have structures at levels anterior to the notochord.

\section{Materials and methods}

Generation of Otx2 mutant mice

To construct the targeting vector, the EcoRI-BamHI fragment of pKJ2 (Boer et al. 1990) containing the neo gene with the phosphoglycerate kinase gene promoter and without the polyadenylation signal was inserted into the KpnI site of the Otx2 gene by blunt-end ligation; the neor gene was oriented in the same direction as the Otx2 gene. The TT2 ES cells were cultured, electroporated with the NotI-linearized targeting vector, and selected against G418 as described (Nada et al. 1993; Yagi et al. 1993b). Homologous recombinants were assessed by PCR analysis with a sense strand oligonucleotide of the $n e o^{\mathrm{r}}$ gene (5'-GCCTGCTTGCCGAATATCATGGTGGAAAAT) and an antisense strand oligonucleotide of the Otx2 intron sequence (5'-AACGAGAGTATCTGCACAGATACTG) as primers to detect the 920 -bp fragment. Chimeras were generated from two independent recombinant clones, B2 and E33, as described (Yagi et al. 1993a). Because there was no difference between mice derived from these two clones, no reference was made as to which clones were used in each experiment. The mice were housed in environmentally controlled rooms of the Laboratory Animal Research Center of Kumamoto University Medical School under the guidelines of Kumamoto University for animal and recombinant DNA experiments.

\section{Genotyping of wild-type and mutant alleles}

Genotypes of newborn mice and embryos were routinely assessed by PCR analyses and confirmed, when necessary, by Southern blot analyses with genomic DNAs prepared from tails or yolk sacs. In PCR analysis, the wild-type allele was detected as the 96-bp product with primers in the sense strand oligonucleotide of the Otx2 gene (5'-CGACGTTCTGGAAGCTCT- 
GTTTGCCAAGAC) and the antisense strand oligonucleotide of the Otx2 gene $\left(5^{\prime}\right.$-GCACCCTGGATTCTGGCAAGTTGATTTTCA). The mutant allele was identified as a 140-bp product with primers in the sense strand oligonucleotide of the neor gene $\left(5^{\prime}\right.$-TCGTGCTTTACGGTATCGCCGCTCCCGATT-3') and the above antisense strand oligonucleotide of the Otx2 gene.

\section{Skeletal analysis and histology}

Cartilages and bones were stained with alcian blue and alizarin red by the method of Kelly et al. (1983) and stored in $80 \%$ glycerol. For histological analyses, mouse embryos were fixed in Bouin's fixative, dehydrated, and embedded in paraplast. Serial sections (7 or $10 \mu \mathrm{m}$ thick) were made and stained with cresyl violet or hematoxylin and eosin.

\section{Whole-mount immunostaining of the nervous system}

Cranial nerve morphology was examined with monoclonal antibody $2 \mathrm{H} 3$ by the whole-mount immunostaining procedure (Sundin and Eichele 1990). In brief, after fixation with paraformaldehyde and PBS at $4^{\circ} \mathrm{C}$ for 1 day, embryos were washed in $0.9 \% \mathrm{NaCl} /$ distilled water, dehydrated in a series of methanol solutions $(50 \%, 80 \%, 100 \%)$, and stored at $-20^{\circ} \mathrm{C}$ until stained. For staining, the samples were dipped in $2 \mathrm{ml}$ of dimethylsulfoxide (DMSO)/methanol $(1: 1)$ at $0^{\circ} \mathrm{C}$ until they sank and incubated for another $30 \mathrm{~min}$ at room temperature after adding 0.5 $\mathrm{ml}$ of $10 \%$ Triton X-100/distilled water. After washing with TST $[20 \mathrm{~mm}$ Tris- $\mathrm{HCl}$ (pH 8.0), $150 \mathrm{mmN} \mathrm{NaCl}, 0.1 \%$ Triton $\mathrm{X}-100]$, the samples were blocked sequentially with aqueous $1 \%$ periodic acid and $5 \%$ dry nonfat milk in TST (TSTM). The embryos were then incubated with $2 \mathrm{H} 3$ antibody for 2-3 days at a 1/50 dilution in TSTM and then with horseradish peroxidaseconjugated goat anti-mouse IgG (Zymed Lab. Inc.) at a $1 / 200$ dilution in TSTM. After washing with TST, they were preincubated with peroxidase substrate 3,3'-diaminobenzidine (DAB, $100 \mu \mathrm{g} / \mathrm{ml})$ in TS $[20 \mathrm{mM}$ Tris- $\mathrm{HCl}(\mathrm{pH} 8.0), 150 \mathrm{mM} \mathrm{NaCl}]$ for $1 \mathrm{hr}$ and reacted with the same concentration of $\mathrm{DAB}$ and $0.01 \%$ hydrogen peroxide in TS for $20-40 \mathrm{~min}$ at $0^{\circ} \mathrm{C}$. The reaction was stopped by rinsing the embryos with $30 \%$ glycerol/PBS. The stained embryos were put through a series of glycerol/water mixtures and finally into $80 \%$ glycerol containing a trace amount of thymol.

\section{In situ hybridization}

Whole-mount and section in situ hybridizations were performed with digoxigenin probes according to the protocol of Wilkinson (1993). Probes for Otx2 (probe A in Fig. 1), En2 (Davis et al. 1988), T (Herrmann 1991), and Krox-20 (Wilkinson et al. 1989) genes were prepared with an RNA labeling kit (Boehringer Mannheim). Anti-digoxigenin antibodies conjugated with alkaline phosphatase were purchased from Boehringer Mannheim.

\section{Acknowledgments}

The $2 \mathrm{H} 3$ antibody was obtained from the Developmental Studies Hybridoma Bank under contract N01-HD-2-3144 from the National Institute of Child Health and Human Developmnt (NICHD). We thank Drs. Andrew Lumsden and Claudio Stern for their critical reading of our manuscript; Drs. Pierre Chambon, Peter Gruss, Robb Krumlauf, Brigid Hogan, Tomas Jessell, and Denis Doboule for their advice, and Drs. Alexandra Joyner, Bernhard Herrmann, and David Wilkinson for in situ probes.
This work was supported in part by grants-in-aid from the Ministry of Education, Science, and Culture of Japan.

The publication costs of this article were defrayed in part by payment of page charges. This article must therefore be hereby marked "advertisement" in accordance with 18 USC section 1734 solely to indicate this fact.

\section{References}

Allis, E.P. 1923. Are the polar and trabecular cartilages of vertebrate embryos the pharyngeal elements of the mandibular and premandibular arches? I. Anat. 58: 37-51.

Altman, J. and S.A. Bayer. 1986. The development of the rat hypothalamus. Adv. Anat. Embryol. Cell Biol. 100: 1-177.

Ang, S.-L., R.A. Conlon, O. Jin, and J. Rossant. 1994. Positive and negative signals from mesoderm regulate the expression of mouse Otx2 in ectoderm explants. Development 120: 2979-2989.

Bergquist, H. 1932. Zur Molphologie des Zwishenhirns bei niederen Wierbeltieren. Acta Zool. 13: 57-303.

Boer, P.H., H. Potten, C.N. Adra, K. Jardine, G. Mullhofer, and M.W. McBurney. 1990. Polymorphisms in the coding and noncoding regions of murine $p g k-1$ alleles. Biochem. Genet. 28: 299-307.

Cantu, J.M. 1978. Dominant inheritance of holoprosencephaly. Birth Defects 14: 215-220.

Chisaka, O. and M.R. Capecchi. 1991. Regionally restricted developmental defects resulting from targeted disruption of the mouse homeobox gene Hox-1.5. Nature 350: 473-479.

Cohen, M.M. Jr. 1989. Perspectives on holoprosencephaly. Part I. Epidemiology, genetics, and syndromology. Teratology 40: 211-236.

Condie, B.G. and M.R. Capecchi. 1994. Mice with targeted disruptions in the paralogous genes hoxa-3 and hoxd-3 reveal synergistic interactions. Nature 370: 304-307.

Cottrall, K., I. Magrath, and J.A.H. Bootes. 1981. A case of proximal 14 trisomy with pathological findings. J. Ment. Defic. Res. 25: 1-6.

Couly, G.F., P.M. Coltey, and N.M. Le Douarin. 1993. The triplet origin of skull in higher vertebrates: A study in quailchick chimeras. Development 117: 409-429.

Davis, C.A., S.E. Noble-Topham, J. Rossant, and A.L. Joyner. 1988. Expression of the homeo box-containing gene En-2 delineates a specific region of the developing mouse brain. Genes \& Dev. 2: 361-371.

de Beer, G.R. 1931. On the nature of trabecula cranii. Q. I. Microsc. Sci. 74: 701-731.

- 1937. The development of the vertebrate skull. Oxford University Press, Oxford, UK.

Evans, H.E. 1979. Reproduction and prenatal development. In Miller's anatomy of the dog (ed. H.E. Evans and G.C. Christensen), pp. 13-17. W.B. Saunders, Philadelphia, PA.

Figdor, M.C. and C.D. Stern. 1993. Segmental organization of embryonic diencephalon. Nature 363: 630-634.

Finkelstein, R. and N. Perrimon. 1991. The molecular genetics and head development in Drosophila melanogaster. Development 112: 899-912.

Finkelstein, R., D. Smouse, T.M. Capaci, A.C. Sprading, and N. Perrimon. 1990. The orthodenticle gene encodes a novel homeo domain protein involve in the development of the Drosophila nervous system and ocellar visual structures. Genes \& Dev. 4: 1516-1527.

Gans, C. and R.G. Northcutt. 1983. Neural crest and the origin of vertebrates: A new head. Science 220: 268-274.

Goodrich, E.S. 1930. Structure and development of vertebrates. Macmillan, London, UK. 
Hamburger, V. 1961. Experimental analysis of the dual origin of the trigeminal ganglion in the chick embryo. J. Exp. Zool. 148: $91-124$.

Herrmann, B.G. 1991. Expression pattern of the brachyury gene in whole-mount Twis/Twis mutant embyos. Development 113: 913-917.

Ingham, P.W. 1988. The molecular genetics of embryonic pattern formation in Drosophila. Nature 335: 25-34.

Juriloff, D.M., K.K. Sulik, T.H. Roderick, and B.K. Hogan. 1985. Genetic and developmental studies of a new mouse mutation that produces otocephaly. I. Craniofacial Genet. Dev. Biol. 5: 121-145.

Kastury, K., T. Druck, K. Huebner, C. Barletta, D. Acampora, A. Simeone, A. Faiella, and E. Boncinelli. 1994. Chromosome locations of human EMX and OTX genes. Genomics 22: 4145.

Kelly, W.L. and M.M. Bryden. 1983. A modified differential stain for cartilage and bone in whole mount preparations of mammalian fetuses and small vertebrates. Stain Technol. 58: 131-134.

Kessel, M. and P. Gruss. 1990. Variations of cervical vertebrae after expression of a Hox-1.1 transgene in mice. Cell 61: 301-308.

Kuratani, S. 1989. Development of the orbital region in the chondrocranium of Caretta caretta. Reconsideration of the vertebrate neurocranium configuration. Anat. Anz. 169: 335-349.

Le Douarin, N. 1982. The neural crest. Development and cell biology series; 12. Cambridge University Press, London, UK.

Little, C.C. and H. Bagg. 1924. The occurrence of four inheritable morphological variations in mice and their possible relation to treatment with X-rays. J. Exp. Zool. 41: 45-91.

Lufkin, T., A. Dierich, M. Lemeur, M. Mark, and P. Chambon. 1991. Disruption of the Hox-1.6 homeobox gene results in defects in a region corresponding to its rostral domain of expression. Cell 66: 1105-1119.

Lumsden, A., N. Sprawson, and A. Graham. 1991. Segmental origin and migration of neural crest cells in the hindbrain region of the chick embryo. Development 113: 1281-1291.

Marshall, A.M. 1882. Segmental value of cranial nerves. J. Anat. Physiol. 16: 305-354.

McGinnis, W. and R. Krumlauf. 1992. Homeobox genes and axial patterning. Cell 68: 283-302.

Nada, S., T. Yagi, H. Takeda, T. Tokunaga, H. Nakagawa, Y. Ikawa, M. Okada, and S. Aizawa. 1993. Constitutive activation of src family kinases in mouse embryos that lack csk. Cell 73: 1125-1135.

Noden, D.M. 1983. The role of the neural crest in patterning of avian cranial skeletal, connective, and muscle tissues. Dev. Biol. 96: 144-165.

- 1984. The use of chimeras in analyses of craniofacial development. In Chimeras in developmental biology /ed. N. LeDouarin and A. McLaren), pp. 241-280. Academic Press, London, UK.

Osumi-Yamashita, N., Y. Ninomiya, H. Doi, and K. Eto. 1994. The contribution of both forebrain and midbrain neural crest cells to the mesenchyme in the frontonasal mass of mouse embryos. Dev. Biol. 164: 409-419.

Piatt, J. 1945. Origin of the mesencephalic V root cells in Amblystoma. I. Comp. Neurol. 82: 35-54.

Puelles, L. and L.R. Rubenstein. 1993. Expression patterns of homeobox and other putative regulatory genes in the embryonic mouse forebrain suggest a neuromeric organization. Trends Neurosci. 16: 472-479.

Rijli, F.M., M. Mark, S. Lakkaraju, A. Dierich, P. Dollé, and P. Chambon. 1993. Homeotic transformation is generated in the rostral branchial region of the head by disruption of Hoxa-2, which acts as a selector gene. Cell 75: 1333-1349.

Romer, A.S. and T.S. Parsons. 1949. The vertebrate body. W.B. Saunders, Philadelphia, PA.

Shawlot, W. and R.R. Behringer. 1995. Requirement for Lim1 in head-organizer function. Nature 374: 425-430.

Simeone, A., D. Acampora, M. Gulisano, A. Stornaiuolo, and E. Boncinelli. 1992. Nested expression domains of homeobox genes in developing rostral brain. Nature 358: 687-690.

Simeone, A., D. Acampora, A. Mallamaci, A. Stornaiuolo, M.R. D'Apice, V. Nigro, and E. Boncinelli. 1993. A vertebrate gene related to orthodenticle contains a homeodomain of the bicoid class and demarcates anterior neuroectoderm in the gastrulating mouse embryo. EMBO J. 12: 2735-2747.

Sulik, K.K., M.C. Johnston, and M.A. Webb. 1981. Fetal alcohol syndrome: Embryogenesis in a mouse model. Science 214: 936-938.

Sundin, O. and G. Eichele. 1990. A homeo domain protein reveals the metameric nature of the developing chick hindbrain. Genes \& Dev. 4: 1267-1276.

Tan, S.S. and G.M. Morriss-Kay. 1985. The development and distribution of the cranial neural crest in the rat embryo. Cell Tiss. Res. 240: 403-416.

Weinberg, E. 1928. The mesencephalic root of the fifth nerve a comparative study. I. Comp. Neurol. 46: 249-405.

Wilkinson, D.G. 1993. In situ hybridization. In Essential developmental biology: A practical approach (ed. C.D. Stern and P.W.H. Holland), pp. 257-274. IRL Press, Oxford, UK.

Wilkinson, D.G., S. Bhatt, P. Charvrier, R. Bravo, and P. Charnay. 1989. Segment specific expression of a zinc finger gene in the developing nervous system of the mouse. Nature 337: 461-464.

Windle, W.F. and M.F. Austin. 1936. Neurofibrillar development in the central nervous system of chick embryos up to 5 days' incubation. J. Comp. Neurol. 63: 431-463.

Wright, S. and K. Wagner. 1934. Types of subnormal development of the head from inbred strains of guinea pigs and their bearing on the classification and interpretation of vertebrate monsters. Am. J. Anat. 54: 383-447.

Yagi, T., T. Tokunaga, Y. Furuta, S. Nada, M. Yoshida, T. Tsukada, Y. Saga, N. Takeda, Y. Ikawa, and S. Aizawa. 1993a. A novel ES cell line, TT2, with high germline-differentiating potency. Anal. Biochem. 214: 70-76.

Yagi, T., S. Nada, N. Watanabe, H. Tamemoto, N. Kohmura, Y. Ikawa, and S. Aizawa. 1993b. A novel negative selection for homologous recombinants using diphtheria toxin A fragment gene. Anal. Biochem. 214: 77-86. 


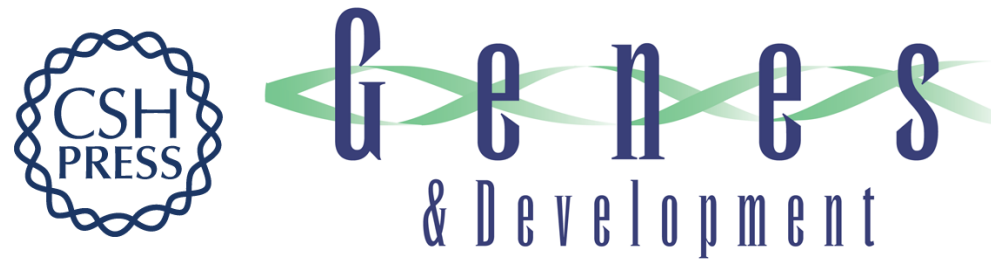

\section{Mouse Otx2 functions in the formation and patterning of rostral head.}

I Matsuo, S Kuratani, C Kimura, et al.

Genes Dev. 1995, 9:

Access the most recent version at doi:10.1101/gad.9.21.2646

References This article cites 48 articles, 9 of which can be accessed free at: http://genesdev.cshlp.org/content/9/21/2646.full.html\#ref-list-1

License

Email Alerting

Receive free email alerts when new articles cite this article - sign up in the box at the top Service right corner of the article or click here.

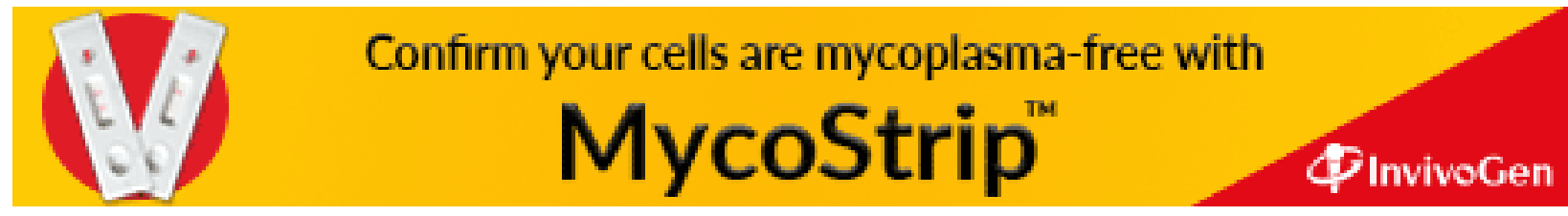

